\title{
Extended thymectomy with blood vessel resection and reconstruction improves therapeutic outcome for clinical stage III thymic carcinoma patients: a real-world research
}

\author{
Lei Liu, Jiaqi Zhang, Guige Wang, Chao Guo, Yeye Chen, Cheng Huang and Shanqing Li ${ }^{*}$
}

\begin{abstract}
Objectives: We examine the therapeutic efficacy of extended thymectomy with blood vessel resection and reconstruction in thymic carcinoma patients with great vessel invasion.

Methods: In total 26 patients diagnosed as clinical stage III thymic carcinoma with severe great vessel invasion were enrolled in this retrospective study. Among these patients, 14 cases received adjuvant chemo- and radiotherapy (non-operation subgroup, NOG), the other 12 patients received extended thymectomy with vessel resection and reconstruction followed by the adjuvant treatment (operation subgroup, OG).

Results: All surgical procedures went smoothly with no perioperative death. R0 resection was obtained in all surgical cases, and we also observed a lymph node metastasis rate of $38.8 \%$. The overall survival (OS) was 34 months for the whole cohort, 48 and 26 months for the OG and NOG respectively $(p=0.013)$. The median disease metastasis free survival (DMFS) was 47 months for the OG and 18 months for the NOG $(p=0.019)$.

Conclusion: Extended thymectomy with vessel resection is feasible for patients with clinical stage III thymic carcinoma. Surgery significantly improves the overall survival and the prognosis of clinical stage III thymic carcinoma.
\end{abstract}

Keywords: Thymic carcinoma, Mediastina, Surgery, Vessel reconstruction, Prognosis

\section{Introduction}

Thymic tumor is one of the most common neoplasms in anterior superior mediastinum, which accounts for $20 \%$ of all mediastinal tumors [1]. In adults, about $50 \%$ of anterior mediastinum tumors are thymic tumors. Previous studies have revealed its association with Epstein-Barr virus infections $[2,3]$. However, thymic carcinomas are rare and only

\footnotetext{
* Correspondence: lishanging2016@126.com

Department of Thoracic Surgery, Peking Union Medical College Hospital, Chinese Academy of Medical Sciences and Peking Union Medical College, Shuaifuyuan No. 1, Wangfujing Street, Dongcheng district, Beijing, P.R. China
}

represent 0.2 to $1.5 \%$ of total human malignancies [4]. Pathological subtypes of thymic malignant tumors are generally defined as low- and high-grade. Specifically, lowgrade thymic malignancies include squamous cell carcinoma, muco-epidermoid carcinoma, and basaloid carcinoma, whereas lymphoepithelioma-like carcinoma, small cell carcinoma, sarcomatoid tumors, clear cell carcinomas, and undifferentiated tumors belong to the high-grade thymic tumor category [5].

Thymic carcinoma patients rarely exhibit obvious clinical manifestations; therefore, these patients are usually

(c) The Author(s). 2020 Open Access This article is licensed under a Creative Commons Attribution 4.0 International License, which permits use, sharing, adaptation, distribution and reproduction in any medium or format, as long as you give appropriate credit to the original author(s) and the source, provide a link to the Creative Commons licence, and indicate if changes were made. The images or other third party material in this article are included in the article's Creative Commons licence, unless indicated otherwise in a credit line to the material. If material is not included in the article's Creative Commons licence and your intended use is not permitted by statutory regulation or exceeds the permitted use, you will need to obtain permission directly from the copyright holder. To view a copy of this licence, visit http://creativecommons.org/licenses/by/4.0/. The Creative Commons Public Domain Dedication waiver (http://creativecommons.org/publicdomain/zero/1.0/) applies to the data made available in this article, unless otherwise stated in a credit line to the data. 
unfavorably identified and diagnosed. Only about one third of thymic malignancy patients develop local symptoms or systemic symptoms [6]. Clinically, the optimal treatment for thymic tumors is surgical operation [7]. However, because of the complexity of anatomical features and vascular distribution in the mediastinum, especially when great vessels are invaded, such surgeries are very challenging to perform, and, in many cases, the tumor is unresectable. All these factors strongly contribute to the poor prognosis for thymic carcinoma. Here, we review thymic carcinoma patients that showed severely invaded great vessels of mediastinum in our center during the past 20 years, and evaluate the efficacy of extended thymectomy with vessel resection and reconstruction for thymic carcinoma patients with great vessel invasions. This study focused on the clinical III stage thymic carcinoma patients with great vessel invasion and analyzed the significance of extended thymectomy with great vessel resection and reconstruction for prognosis.

\section{Materials and methods Patients}

We reviewed 292 cases of thymic malignancy diagnosed and treated in our center from 1997 to 2017. Of the above patients, 18 were stage I,22 were stage II,65 were stage III and 187 were stage IV. In total, 26 patients diagnosed as clinical stage III thymic malignant tumors by Masaoka stage system with only severe great vessel invasion were selected for this study. 14 of these patients were treated with regular chemo- and radiotherapy and allocated to the non-operation subgroup (NOG); the other 12 patients, who were assigned to the operation subgroup (OG), underwent extended thymectomy with vessel resection and reconstruction as well as routine therapy. The preoperative preparation included enhanced chest CT examination, cardiopulmonary function test and elimination of stage IV thymic carcinoma. We assess resectability by enhanced chest $\mathrm{CT}$, and if the mass was considered to be completely resectable, no biopsy was performed before operation.

\section{Procedures for extended thymectomy with vessel resection and reconstruction}

Following general anesthesia and endotracheal intubation, median sternotomy incision was performed for all the patients in the operation group. In line with preoperative imaging examination, we observed that tumors grew invasively and displayed unclear boundaries with surrounding tissue. Rather than attempting to separate the tumor from the great vessels completely, we decided to perform vascular resection and reconstruction. The operation strategy was to dissociate tumor tissue with invaded vessels preferentially prior to carrying out vessel resection and reconstruction. Tumor and thymic tissues were firstly isolated with the invaded innominate vein or superior vena cava (SVC) followed by blocking the distal end and proximal part of the invaded vessel at the safe edge where the tumor did not invade. When left innominate vein (LIV) was invaded and resected, different approaches were applied for vessel reconstruction, such as LIV- auricula dextra, LIV-atrium dextra and LIV-SVC. If the right innominate vein (RIV) was resected, the major approach for reconstruction was RIV-SVC, except for 1 patient, who underwent RIV- auricula dextra reconstruction. The diameter of the graft ranged in size from 8 to $14 \mathrm{~mm}$, and the choice was decided according to personalized situation during the surgery and $2-4 \mathrm{~mL}$ heparin was injected intravenously during bypass grafting in all patients. Polytetrafluoroethylene (PTFE) material was used for vessel reconstruction and autologous pericardium was applied to patch great vessel walls. The great vessels were reconstructed with 4-0 or 5-0 prolene by continuous eversion suture, before which $125 \mathrm{U} / \mathrm{mL}$ heparin saline was used to immerse vascular graft prior to vessel reconstruction. If bilateral innominate veins were invaded, LIV was resected and reconstructed preferentially. The SVC blocking time of all the cases were $<$ $40 \mathrm{~min}$, and mostly $<30 \mathrm{~min}$.

\section{Postoperative treatment}

Subcutaneous injection of heparin was administrated to the patients early post-operation according to the severity of chest drainage. For patients with head and neck edema, oral diuretics were given as treatment. In particular, warfarin was given to all patients in the non-operation group as an anticoagulant for 2 months to maintain the international normalized ratio (INR) of prothrombin time of blood coagulationbetween 1.8 to 2.5 and to prevent thrombosis or bleeding complications. The follow-up examination was carried out every 6 months and consisted of CT scans for chest and abdomen to monitor tumor recurrence or metastasis.

For the patients in the OG, postoperative adjuvant chemotherapy and radiotherapy were performed according to their pathological results and intraoperative conditions. The chemotherapy regimen used in this study was mainly TP (Paclitaxel + Cisplatin) or DDP + VP16 (Cisplatin + Etoposide). Total doses of postoperative radiotherapy were 50 Gy in 25 fractions by fixed-field intensity-modulated radiation technology.

\section{Statistics analysis}

Overall survival (OS) is defined as the time from the start of treatment to the date of death or to the date of censoring. Distant metastasis-free survival (DMFS) is defined as the beginning of radiotherapy to the detection of distant metastasis or distant metastasisrelated death. OS and DMFS were calculated with the 
Kaplan-Meier method by using SPSS 24.0 statistical software and compared using the log-rank test. Chisquare test was used to detect differences between groups. $P$ value $<0.05$ was considered statistically significant.

\section{Results}

\section{General situation of enrolled patients}

All patients' information, including age, sex, clinical symptoms, pathological characters, and operation status are summarized in Table 1 . Of the 26 patients enrolled, 19 were male and 7 were female. The mean age of the patients was 52 years (ranging from 20 to 67 years). The diameter range of tumor was between 3.7 to $16.2 \mathrm{~cm}$ and the median diameter of tumor was $6 \mathrm{~cm}$. The chi-square test for differences in basic characteristics between the two subgroups is shown in Table 2. Pathological types of thymic carcinoma tumors include squamous cell carcinoma (14/26), atypical carcinoid (5/26), basaloid carcinoma (2/26) and undifferentiated carcinoma (5/26). In the OG, all the 12 pathological reports showed negative margin of tumor. In addition, a total of 6 patients in the OG had lymph node metastasis, with a lymph node metastasis rate of $38.8 \%(26 / 67)$. There was no statistical difference between the two groups in terms of chemotherapy or radiotherapy regimen.

\section{Extended thymectomy with vessel resection and reconstruction}

Surgical procedures were successful for all patients who received extended thymectomy with great vessel resection and reconstruction, (Table 3). The operation time was between 220 and $405 \mathrm{~min}$, with a mean operation time of $335.83 \mathrm{~min}$. The median postoperative hospital stay was 11.5 days. 7 patients received blood transfusions during the operation, with an average usage of $3 \mathrm{U}$ red blood cells and $266.7 \mathrm{~mL}$ plasma, while the mean

Table 1 General situation of included patients

\begin{tabular}{|c|c|c|c|c|c|c|c|}
\hline No. & Gender & Age (yrs) & Symptoms & Diameter (cm) & Pathology diagnose & Operation & Status \\
\hline 1 & Male & 59 & Chest pain & 5 & Basaloid carcinoma & Y & Stable \\
\hline 2 & Male & 51 & Back pain & 7.4 & Squamous-cell carcinoma & Y & Dead \\
\hline 3 & Female & 46 & Back pain & 5.5 & Squamous-cell carcinoma & Y & Stable \\
\hline 4 & Male & 55 & Chest pain & 3.7 & Atypical carcinoid & Y & Stable \\
\hline 5 & Male & 40 & Asymptomatic & 7 & Atypical carcinoid & Y & Stable \\
\hline 6 & Female & 47 & Myasthenia gravis & 7 & Squamous-cell carcinoma & Y & Stable \\
\hline 7 & Male & 34 & Chest distress & 5.5 & Squamous-cell carcinoma & Y & Stable \\
\hline 8 & Male & 43 & Superior vena cava syndrome & 5 & Atypical carcinoid & Y & Dead \\
\hline 9 & Female & 52 & Myasthenia gravis & 6 & Squamous-cell carcinoma & Y & Stable \\
\hline 10 & Male & 23 & Superior vena cava syndrome & 7.2 & Undifferentiated carcinoma & Y & Dead \\
\hline 11 & Male & 26 & Hypokalemia & 5 & Undifferentiated carcinoma & Y & Dead \\
\hline 12 & Female & 52 & Asymptomatic & 5 & Squamous-cell carcinoma & Y & Stable \\
\hline 13 & Male & 53 & Chest pain & 12.7 & Squamous-cell carcinoma & $\mathrm{N}$ & Dead \\
\hline 14 & Male & 65 & Myasthenia gravis & 5.8 & Squamous-cell carcinoma & $\mathrm{N}$ & Dead \\
\hline 15 & Male & 46 & Asymptomatic & 4.2 & Undifferentiated carcinoma & $\mathrm{N}$ & Dead \\
\hline 16 & Male & 53 & Shoulder Pain & 6.9 & Squamous-cell carcinoma & $\mathrm{N}$ & Dead \\
\hline 17 & Male & 58 & Asymptomatic & 5.8 & Atypical carcinoid & $\mathrm{N}$ & Dead \\
\hline 18 & Female & 62 & Myasthenia gravis & 6 & Squamous-cell carcinoma & $\mathrm{N}$ & Stable \\
\hline 19 & Female & 59 & Asymptomatic & 9.2 & Squamous-cell carcinoma & $\mathrm{N}$ & Dead \\
\hline 20 & Male & 67 & Chest pain & 6 & Undifferentiated carcinoma & $\mathrm{N}$ & Dead \\
\hline 21 & Male & 51 & Chest distress & 16.2 & Squamous-cell carcinoma & N & Stable \\
\hline 22 & Male & 53 & Superior vena cava syndrome & 5 & Undifferentiated carcinoma & $\mathrm{N}$ & Lung metastasis \\
\hline 23 & Female & 39 & Asymptomatic & 6.6 & Basaloid carcinoma & $\mathrm{N}$ & Dead \\
\hline 24 & Male & 53 & Chest pain & 8.7 & Squamous-cell carcinoma & $\mathrm{N}$ & Lung metastasis \\
\hline 25 & Male & 60 & Chest pain & 9.4 & Squamous-cell carcinoma & $\mathrm{N}$ & Dead \\
\hline 26 & Male & 20 & Myasthenia gravis & 5.5 & Atypical carcinoid & $\mathrm{N}$ & Stable \\
\hline
\end{tabular}


Table 2 Chi-square test of two groups of basic characteristics

\begin{tabular}{|c|c|c|c|c|}
\hline Characteristics & Total & OG & NOG & $p$ \\
\hline \multicolumn{5}{|l|}{ Sex } \\
\hline Male & 19 & 8 & 11 & 0.495 \\
\hline Female & 7 & 4 & 3 & \\
\hline \multicolumn{5}{|l|}{ Age } \\
\hline$<52$ years old & 12 & 8 & 4 & 0.052 \\
\hline$\geq 52$ year old & 14 & 4 & 10 & \\
\hline \multicolumn{5}{|l|}{ Tumor diameter } \\
\hline$<6 \mathrm{~cm}$ & 12 & 7 & 5 & 0.249 \\
\hline$\geq 6 \mathrm{~cm}$ & 14 & 5 & 9 & \\
\hline
\end{tabular}

amount of bleeding was $979.2 \mathrm{~mL} .6$ cases had multiple vessel reconstructions resulting in a total of 18 vessel replacements. After the surgery, 10 patients received adjuvant therapy, including 6 cases of radiotherapy, 1 case of chemotherapy, and 3 cases of radio-chemotherapy. Of note, there was 1 patient developed a graft thrombus and was re-operated. A representative image of the blood vessel reconstruction is presented (Fig. 1-a), moreover, the typical CT scan results before and after the surgery for 1 selected patient (Fig. 1-b,c) showing not only that the vessel reconstruction was performed satisfactorily but also that no local recurrence is visible.

Table 3 Operation Status of OG

\begin{tabular}{ll}
\hline Variable & Numerical value \\
\hline Time of operation, min (range) & $335.83(220-405)$ \\
Postoperative hospital stay, day (range) & $11.5(4-46)$ \\
Diameter of vessel replaced & \\
$8 \mathrm{~mm}$ & $13(72.22 \%)$ \\
$12 \mathrm{~mm}$ & $4(22.22 \%)$ \\
$14 \mathrm{~mm}$ & $1(5.56 \%)$ \\
Amount of bleeding, ml (range) & $979.17(200-2500)$ \\
Method of vessel reconstruction & \\
LIV- auricula dextra & $6(33.34 \%)$ \\
LIV- atrium dextra & $2(11.11 \%)$ \\
LIV-SVC & $2(11.11 \%)$ \\
RIV-SVC & $7(38.88 \%)$ \\
RIV- auricula dextra & $1(5.56 \%)$ \\
Resected Vessels & \\
LIV & $4(33.33 \%)$ \\
RIV & $2(16.67 \%)$ \\
LIV + RIV + SVC & $6(50.00 \%)$ \\
Blood transfusion & \\
RBC, U (range) & $3(0-9)$ \\
Plasma, ml (range) & $266.67(0-1000)$ \\
\hline
\end{tabular}

LIV left innominate vein, SVC superior vena cava, RIV right innominate vein
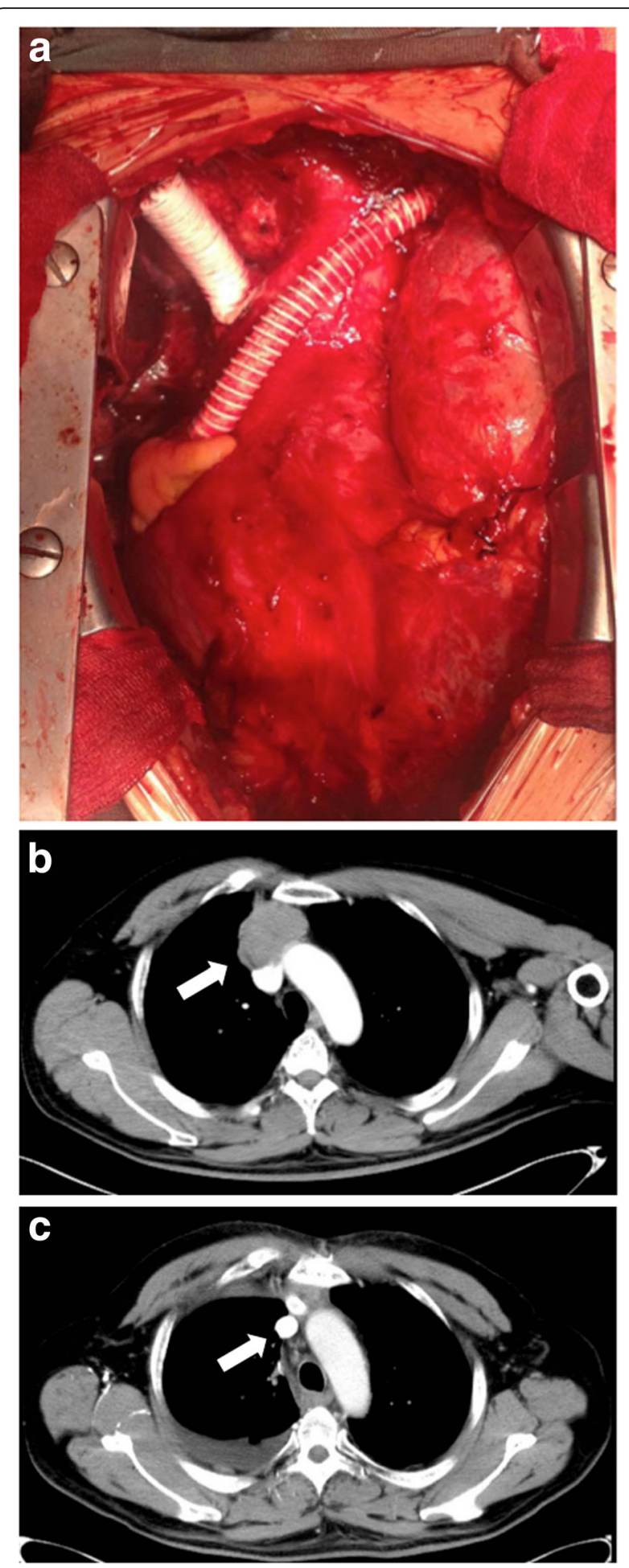

Fig. 1 Blood vessel resection and reconstruction. a A representative image of the vessel reconstruction after the surgery. $\mathbf{b} C T$ scan results for a selected patient from the experiment group before the surgery. The arrow indicates the tumor area. c CT scan results for a selected patient from the experiment group at the same position after the surgery for six months 
Prognosis for clinical stage III thymic malignancy patients with great vessel invasion

The median follow-up time of patients was 44 months (ranging from 21 to 143 months). For the 14 patients in the NOG, we observed 9 deaths with distant metastasis of different sites was observed before death by the time of the last follow up and 2 patients exhibited lung metastasis. In contrast, among the 12 patients from OG, except for one patient who died of acute respiratory failure 1 month after surgery, 3 patients had died at the time of the last follow up with thoracic cavity, liver or bone metastasis. The other 8 patients from the OG showed no metastasis or local recurrence of the disease. To the date of the last follow up, the survival rate was $66.67 \%$ for the OG and $35.71 \%$ for the NOG. The median OS of the 26 patients is 34 months (range 1 to 135 months), it is 48 months for the OG and 26 months for the NOG. The overall median DMFS is 28 months while it is 47 months for the OG and 18 months for the NOG. The differences in OS and DFMS between the two subgroups are significant ( $p=0.013$ and $p=0.019$ respectively) (Fig. 2-a,b).

\section{Discussion}

Although the occurrence is low, thymic tumors are one of the most frequent mediastinal neoplasms, and account for $5 \%$ of all thymic malignancies [8]. Venuta et al. have reported that approximately $30 \%$ of patients with thymic malignancies are asymptomatic, $40 \%$ of them show local symptoms, and only $30 \%$ exhibit systemic symptoms [9]. Thus, except for those displaying systemic symptoms such as myasthenia or pure red cell aplasia, many thymic malignancy patients lack clinical manifestations. Therefore, a large number of thymic carcinoma is of relatively late stage at the time of diagnosis. In this study, 17 patients were asymptomatic or had mild clinical symptoms such as chest-back pain and chest tightness, accounting for $65.39 \%$ of all patients. Besides, for adhesion to great vessels like SVC and characteristics of aggressive growth of malignant tumors, thymic carcinoma are very difficult to completely remove which leads to a poor prognosis. We retrospectively analysis 26 patients with thymic carcinoma diagnosed as clinical stage III due to great vessel invasion to study the effects of different treatments on prognosis in real-world.

Extended thymectomy was first proposed by Masaoka in 1981, he defined it as the removal of the extracapsular fat with the intra-capsular thymus gland, for eliminating as much thymic tissue as possible [10]. In 1996, Masaoka consolidated the concept as resection of the anterior mediastinal fat tissue, which includes the thymus; the operation was performed bluntly from pericardium and pleura. In the procedure of external thymectomy he described, adipose tissues around the upper poles of the thymus, around both brachiocephalic veins, and on the pericardium were resected meticulously. If necessary, the pleural cavity was entered. The borders of resection were the diaphragm caudally, the thyroid gland orally, and the phrenic nerves laterally [11]. Thymectomy in now routinely used for the resection of mediastinal tumors [12, 13]. Additionally, extended thymectomy is the most acceptable and efficient therapy for thymic carcinoma [14].

Involvement of the great vessels has been found to be an independent negative prognostic factor [15] and favors the onset of recurrence [16] in thymic carcinoma. Great vessel invasion do not only increases the difficulty and risk of the operation, but can even sometimes completely preclude it. Previous studies have reported on great vessel resection and reconstruction but most of them were case reports $[17,18]$. Due to the unsatisfactory effect of radiotherapy and chemotherapy, we did our best to perform surgical treatment for the 12 patients in the study. According to our observations, the most commonly invaded vessel is the LIV due to the proximal anatomical feature. Although the operation went fine, it remains a difficult procedure, as can be appreciated from the amount of bleeding and blood transfused during the operation. After reviewing the procedure, we could conclude that the extended thymectomy with blood vessel resection and reconstruction can be completed following a defined procedure; we therefore propose that the operation could be normalized and popularized.

Previous research showed that a tumor diameter larger than $8 \mathrm{~cm}$ is a risk factor for recurrence $[19,20]$, while complete resection of a tumor is extremely important for improving prognosis [21-23]. The study of Bacha et al. retrospectively analyzed 89 patients who underwent total or subtotal resection of a primary mediastinal tumor and suggested median sternotomy as an excellent surgical approach [24]. To achieve such a goal and assure safety during the surgery, we adopted median sternotomy for all the patients, which allowed vessel resection and reconstruction and ensured the range of extended thymectomy. At present, there is no clear definition of surgical indications in the latest guidelines, whether thymic carcinoma can be operated depends to a large extent on the surgeon's appreciation. However, in our retrospective study, there was no significant difference in tumor diameter between the two groups $(p=$ 0.249). In real clinical practice, tumor diameter will become one of the factors that influence the surgeon decisions, especially on the issue of resectability.

Rajan et al. indicated that resection of the entire tumor by complete thymectomy and removal of all surrounding mediastinal fat as well as surrounding pleura increased the chances of achieving negative surgical margins [1]. Among the 12 thymic carcinoma patients who 

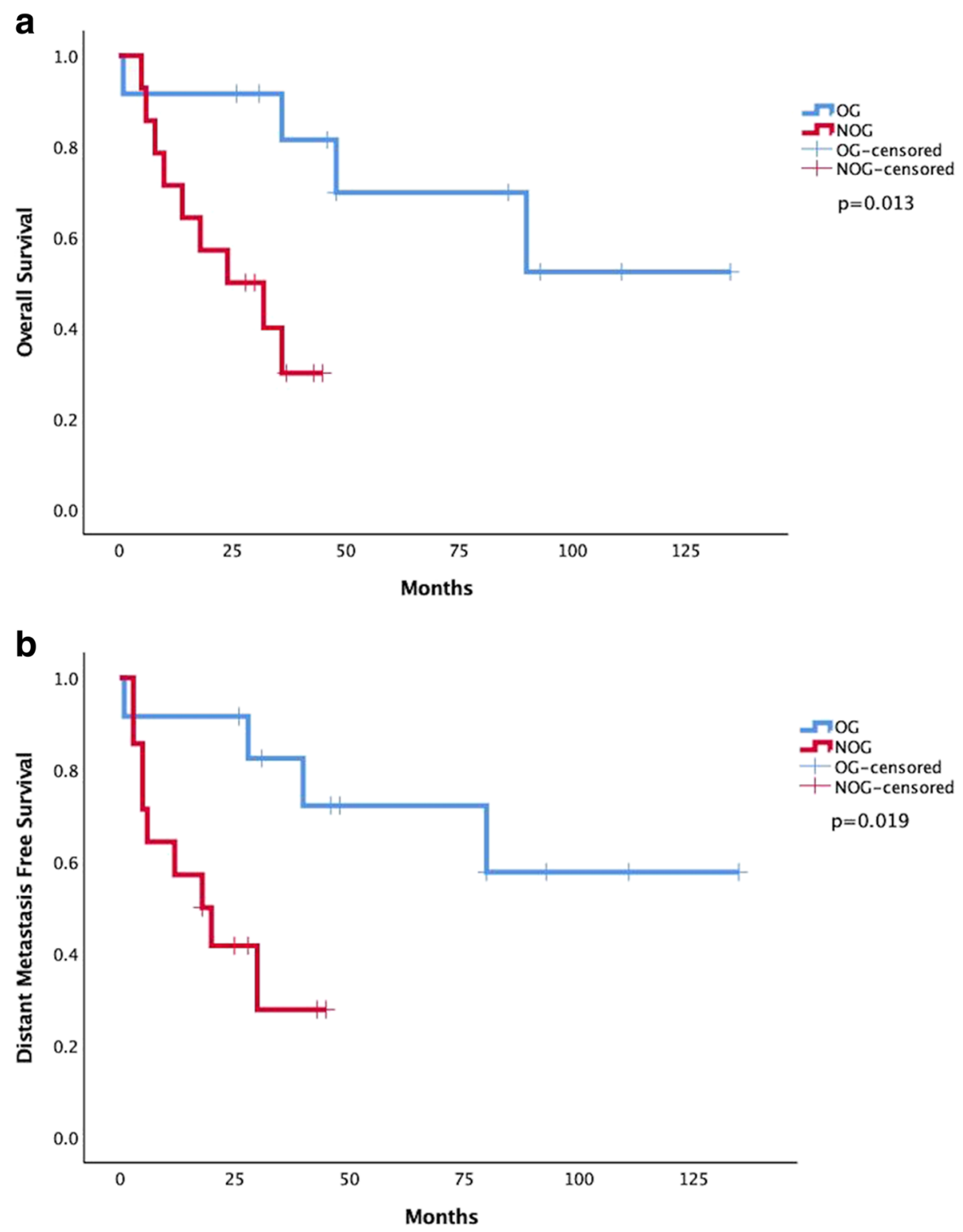

Fig. 2 The Comparison of prognosis between control and experiment group. a Overall survival (OS) in the control group and experiment group, $P=0.013$. b Distant metastasis free survival (DMFS) in the control group and experiment group, $P=0.019$

underwent operation, all of them had a complete tumor resection with grossly and pathologically confirmed negative resection margins. However, due to the large volume of the tumor, we still can't certainly exclude the possibility of R1 resection. Some researchers have demonstrated that postoperative radiotherapy reduced thymic malignancy recurrence [25]. In order to reduce postoperative relapse and metastasis, 10 patients received adjuvant therapy, including 6 cases of radiotherapy, 1 case of chemotherapy and 3 cases of radiochemotherapy. A multicenter study based on a Chinese population found that the lymph node metastasis rate of thymic carcinoma could be as high as $25 \%$, and after intentional lymph node dissection or sampling, the lymph node metastasis rate increased significantly [26]. In this study, the rate of lymph node metastasis was higher (38.8\%). We believe that this is associated with the higher overall stage of our cohort, but the above data all suggest the importance of lymph node dissection in thymic carcinoma surgery.

Most patients of the OG had a graft diameter of 8 $\mathrm{mm}$, compared to $12 \mathrm{~mm}$ or $10 \mathrm{~mm}$ vascular prosthesis used in the studies carried out by Bacha et al. [24]. and Shintani et al. [27]. There is no standard procedure to determine the diameter of artificial vessels. We decided on the diameter for vascular replacement based on the 
intraoperative evaluation of the invaded vascular. The diameter of artificial blood vessels in the OG was relatively fine due to the Asians figure. However, we experienced 1 patient who had acute thrombosis after surgery and was re-operated with a $12 \mathrm{~mm}$ graft replacement, as the reconstructed vessel might have been too small for the patient. Previous studies suggested systematic administration of heparin before vessel replacement [17, $18,24]$, we also gave $2-4 \mathrm{ml}$ heparin during the operation and subcutaneous heparin after the operation to prevent embolism. In addition, oral warfarin was given for 2 months for anticoagulation to maintain the INR between 1.8-2.5. To prevent thrombosis, all grafts were immersed in $125 \mathrm{U} / \mathrm{ml}$ heparin saline before vessel reconstruction. To date, with the long-term follow-ups, no severe vascular stenosis in the reconstructed vessels was observed.

Chung et al. reported that the median survival for patients with stage III thymic malignancy incompletely or not resected and invading neighboring organs was 26.1 months [28]. Eng et al. concluded that five-year survival rates for thymic carcinoma were approximately 30 to $50 \%$ [29]. Similarly, previous literature reported that the overall 5 -year survival rate was $42 \%$ for thymic carcinoma patients [24]. In our study, we compared the prognosis between the two subgroups: in OG, 4 patients died and suffered thoracic cavity, liver or bone metastasis by the time of the last follow-up; in contrast, 9 patients died, and 2 patients showed metastasis in the NOG. To the date of the last follow up, the survival rate is 66.67 and $35.71 \%$ for the OG and NOG respectively. The median OS of all patients included is 34 months; whereas OS of OG is significantly longer than NOG (48 vs. 26 months, $p=0.013)$. DMFS of OG is also significantly longer than NOG (47 vs. 18 months, $p=0.019$ ). The main recurrence pattern of thoracic adenocarcinoma is in situ relapse. Results above suggest that extended thymectomy with vessel resection and reconstruction can significantly improve the prognosis of clinical stage III thymic malignancy with great vessel invasion, and reduce the probability of metastasis.

This study has several limitations. First, due to low incidence of thymic carcinoma, and the study inclusion criteria that were limited to patients with clinical stage III thymic carcinoma, the patient cohort is small. Second, since this is a retrospective analysis, there will be unavoidable selection bias. We had limited the criteria for inclusion to clinical III thymic carcinoma with only vascular invasion to minimize selection bias. Last but not least, this study failed to continue to explore the impact of clinicopathological features, such as tumor diameter, lymph node metastasis, and pathological type, on the prognosis of patients in the OG.

\section{Conclusion}

Thymic carcinoma patients often lack typical clinical manifestations and are therefore in a relatively advanced stage at the time of initial diagnosis. We conducted a real-world research reviewed the data of clinical stage III thymic carcinoma patients who underwent extended thymectomy with blood vessel resection and reconstruction. We consider that it is feasible to carry this operation for patients at this stage, and it can be popularized as a routine operation manner. We found that surgery can not only improve the prognosis of patients at this stage, but also reduce the probability of distant metastasis. Our data also confirmed the high rate of lymph node metastasis in thymic carcinoma patients and propose intentional lymph node dissection or sampling during thymic carcinoma surgery.

\section{Abbreviations}

NOG: Non-operation subgroup; OG: Operation subgroup; OS: Overall survival; DMFS: Disease metastasis free survival; SVC: Superior vena cava; LIV: Left innominate vein; RIV: Right innominate vein; PTFE: Polytetrafluoroethylene; INR: International normalized ratio

\section{Acknowledgements}

We would like to give our sincere thanks to Professor Hongsheng Liu, Yushang Cui, Naixin Liang, Zhijun Han and Li Li for their contributions to their clinical works.

\section{Authors' contributions}

Conception and design: Shanqing Li; Collection and assembly of data: Lei Liu, Guige Wang, Jiaqi Zhang; Data analysis and interpretation: Lei Liu, Chao Guo, Yeye Chen, Cheng Huang; Manuscript writing: All authors; Final approval of manuscript: All authors;

\section{Funding}

This study was funded by the Translational medicine for individualized diagnosis and treatment of thoracic cancers (311037).

\section{Availability of data and materials}

Not applicable.

\section{Ethics approval and consent to participate}

All procedures performed in studies involving human participants were in accordance with the ethical standards of the research committee of Peking Union Medical College Hospital (PUMCH). This study is approved by the ethical committee of Peking Union Medical College Hospital. Informed consent was obtained from all individual participants included in the study.

\section{Consent for publication}

Not applicable.

Competing interests

The authors declare that they have no competing interests.

Received: 17 July 2020 Accepted: 21 September 2020

Published online: 25 September 2020

\section{References}

1. Rajan A, Giaccone G. Treatment of advanced thymoma and thymic carcinoma. Curr Treat Options in Oncol. 2008;9:277-87.

2. Patton DF, Ribeiro RC, Jenkins JJ, Sixbey JW. Thymic carcinoma with a defective epstein-barr virus encoding the bzlfi trans-activator. J Infect Dis. 1994;170:7-12.

3. Wu TC, Kuo T. Study of Epstein-Barr virus early RNA1 (EBER1) expression by in situ hybridization in thymic epithelial tumors of Chinese patients in Taiwan. Hum Pathol. 1993;24:235-8. 
4. Fornasiero A, Daniele O, Ghiotto C, Fiorentino MV, Piazza M, Fiore-Donati L, et al. Chemotherapy for invasive thymoma. A 13-year experience. Cancer. 1991;68:30-3.

5. Suster S, Rosai J. Thymic carcinoma. A clinicopathologic study of 60 cases. Cancer. 1991;67:1025-32

6. Wilkins KB, Sheikh E, Green R, Patel M, George S, Takano M, et al. Clinical and pathologic predictors of survival in patients with thymoma. Ann Surg. 1999:230:562-72

7. Lucchi M, Basolo F, Mussi A. Surgical treatment of pleural recurrence from thymoma. Eur J Cardio-thoracic Surg. 2008:33:707-11.

8. Engels EA, Pfeiffer RM. Malignant thymoma in the United States: demographic patterns in incidence and associations with subsequent malignancies. Int J Cancer. 2003;105:546-51.

9. Venuta F, Anile M, Diso D, Vitolo D, Rendina EA, De Giacomo T, et al. Thymoma and thymic carcinoma. Eur J Cardio-thoracic Surg. 2010;37:13-25.

10. Masaoka A, Monden Y. Comparison of the results of transsternal imple, transcervical simple, and extended thymectomy. Ann N Y Acad Sci. 1981; 377:755-65

11. Masaoka A, Yamakawa Y, Niwa H, Fukai I, Kondo S, Kobayashi M, et al. Extended thymectomy for myasthenia gravis patients: a 20 -year review. Ann Thorac Surg. 1996;62:853-9.

12. Numanami H, Yano M, Yamaji M, Taguchi R, Furuta C, Nakanishi R, et al. Thoracoscopic thymectomy using a subxiphoid approach for anterior mediastinal tumors. Ann Thorac Cardiovasc Surg. 2018;24:65-72.

13. Narm KS, Lee CY, Do YW, Jung HS, Byun GE, Lee JG, et al. Limited thymectomy as a potential alternative treatment option for early-stage thymoma: a multi-institutional propensity-matched study. Lung Cancer. 2016;101:22-7.

14. Miyata R, Hamaji M, Omasa M, Nakagawa T, Sumitomo R, Huang CL, et al. Survival outcomes after minimally invasive thymectomy for early-stage thymic carcinoma. Surg Today. 2019;49:357-60.

15. Okumura M, Miyoshi S, Takeuchi Y, Yoon HE, Minami M, Takeda I, et al. Results of surgical treatment of thymomas with special reference to the involved organs. J Thorac Cardiovasc Surg. 1999:117:605-13.

16. Utsumi T, Shiono H, Matsumura A, Maeda H, Ohta M, Tada H, et al. Stage III thymoma: relationship of local invasion to recurrence. J Thorac Cardiovasc Surg. 2008;136:1481-5.

17. Takahashi T, Suzuki K, Ito Y, Takinami M, Yamashita K, Kazui T. Aortic arch resection under temporary bypass grafting for advanced Thymic Cancer. Japanese J Thorac Cardiovasc Surg. 2002:50:302-4

18. Oka S, Taira A, Shinohara S, Kuwata T, Takenaka M, Chikaishi Y, et al. Complete resection of Thymic Sarcomatoid carcinoma through Total aortic arch replacement. Ann Thorac Surg. 2016;102:e557-9.

19. Wright CD, Wain JC, Wong DR, Donahue DM, Gaissert HA, Grillo HC, et al. Predictors of recurrence in thymic tumors: importance of invasion, World Health Organization histology, and size. J Thorac Cardiovasc Surg. 2005;130: $1413-2$.

20. Xu C, Feng QF, Fan CC, Zhai YR, Chen YD, Zhang HX, et al. Patterns and predictors of recurrence after radical resection of thymoma. Radiother Oncol. 2015;115:30-4.

21. Lucchi M, Mussi A, Basolo F, Ambrogi MC, Fontanini G, Angeletti CA. The multimodality treatment of thymic carcinoma. Eur J Cardio-thoracic Surg. 2001;19:566-9.

22. Safieddine N, Liu G, Cuningham K, Ming T, Hwang D, Brade A, et al. Prognostic factors for cure, recurrence and long-term survival after surgical resection of thymoma. J Thorac Oncol. 2014;9:1018-22.

23. Juel VC. Myasthenia gravis: management of myasthenic crisis and perioperative care. Semin Neurol. 2004;24:75-81.

24. Bacha EA, Chapelier AR, Macchiarini P, Fadel E, Dartevelle PG. Surgery for invasive primary mediastinal tumors. Ann Thorac Surg. 1998;66:234-9.

25. Huang J, Rizk NP, Travis WD, Riely GJ, Park BJ, Bains MS, et al. Comparison of patterns of relapse in thymic carcinoma and thymoma. J Thorac Cardiovasc Surg. 2009;138:26-31.

26. Fang W, Wang $Y$, Pang L, Gu Z, Wei Y, Liu Y, et al. Lymph node metastasis in thymic malignancies: a Chinese multicenter prospective observational study. J Thorac Cardiovasc Surg. 2018;156:824-33.

27. Shintani $Y$, Ohta M, Minami M, Shiono $H$, Hirabayashi $H$, Inoue $M$, et al. Long-term graft patency after replacement of the brachiocephalic veins combined with resection of mediastinal tumors. J Thorac Cardiovasc Surg. 2005:129:809-12
28. Chung DA. Thymic carcinoma - analysis of nineteen clinicopathological studies. Thorac Cardiovasc Surg. 2000;48:114-9.

29. Eng TY, Fuller CD, Jagirdar J, Bains Y, Thomas CR. Thymic carcinoma: state of the art review. Int J Radiat Oncol Biol Phys. 2004:59:654-64.

\section{Publisher's Note}

Springer Nature remains neutral with regard to jurisdictional claims in published maps and institutional affiliations.
Ready to submit your research? Choose BMC and benefit from:

- fast, convenient online submission

- thorough peer review by experienced researchers in your field

- rapid publication on acceptance

- support for research data, including large and complex data types

- gold Open Access which fosters wider collaboration and increased citations

- maximum visibility for your research: over $100 \mathrm{M}$ website views per year

At BMC, research is always in progress.

Learn more biomedcentral.com/submissions 